\title{
Research funding agencies are redefining science. Early Career Researchers will have to adapt.
}

\author{
Koen Vermeir
}

Research funding agencies do more than just giving funding. So far, the focus of researchers and policy makers has been on how much funding agencies can distribute, ${ }^{1}$ how they allocate it, ${ }^{2}$ and the effects on young researchers and scientists more generally. ${ }^{3}$ It has gone almost unperceived that the reduction of university funding and the increase of project based research has given national research foundations also more clout in the science ecosystem. This increased power is reinforced by coalitions and networks of research funding agencies that facilitate communication and collective action. ${ }^{4}$ They are now discovering that, since they hold the purse and can work together, they have the power to redefine science.

Science has always been a regulated activity. Scientists have adhered to certain norms and values and they have occasionally ostracized those who overstepped the boundaries of appropriate scientific conduct. In recent years, such regulations have become increasingly bureaucratic and research funding agencies have played their part in this evolution. The history of research ethics nicely illustrates how ethical codes became prevalent in the Postwar period after major ethical scandals but such codes became regulative only much later. Research funders, with the help of Research ethics committees, have now become important actors in raising awareness and enforcing regulation around ethical research conduct. In the last five years, research funding agencies have become more activist in regulating research practice beyond ethical considerations. Especially with the launch of Plan S in the summer of 2018, a coalition of funding bodies has aimed at fundamentally changing the publication practices of scientists, and with it, the scientific ecosystem as it currently exists.

Plan S was originally conceived by Robert-Jan Smits, former director-general of the DG Research $\&$ Innovation of the European Commission. In the spring of 2018, he started as the European Commission's Special Envoy for Open Access with the task to create policies to make all publicly funded scientific publications available in Open Access by 2020 . He said: "I want to act decidedly. Everyone agrees on this matter, all European ministers have committed to open access last year in Amsterdam. Let's make it happen." ${ }^{6}$ He started his tenure as Special Envoy consulting with many stakeholders, and during one of these discussions, the CEO of Elsevier unwittingly gave him the key to the solution: if those who control a large part of the research funding could come together and demand Open Access publication, the publishing 
industry would have to follow. ${ }^{7}$ This story may be an embellishment, but it is a fact that a few months later, a new coalition of funding agencies, called cOAlition S, launched Plan S with as its core principle: "all scholarly publications on the results from research funded by public or private grants provided by national, regional and international research councils and funding bodies, must be published in Open Access Journals, on Open Access Platforms, or made immediately available through Open Access Repositories without embargo." ${ }^{8}$

Plan $S$ is a risky but bold move. ${ }^{9}$ Marc Schiltz, the President of Science Europe, and Robert-Jan Smits have claimed that the "S" in Plan S stands for shock, and one could say that the research community and STM publishers were indeed in shock. But the Plan was based on a solid rationale: the scientific publication system is broken and the scientific community urgently needs to find a way to fix it. One aspect of the problem is that scientific journals have become so expensive that libraries and universities cannot pay the subscriptions. Furthermore, no policies or measures taken in the last decade have fundamentally changed the status quo. I will not go deeper into the merits or challenges of Plan S itself, although it could indeed provide the shock necessary to jolt the scientific publication system into a new, more sustainable format.

One important point of critique was that Plan $S$ violates "academic freedom", or less strongly put, that it restricts the "freedom" of researchers to publish where they want. ${ }^{10}$ In response, others have written that funders "have the right to determine how $(\cdots)$ the research they fund should be published: he who pays the piper calls the tune". ${ }^{11}$ Freedom is a big word, and it is questionable whether researchers really enjoyed such freedom, ${ }^{12}$ but the proverbial counterargument may also be too simplistic. Indeed, the critique points to a deeper and more interesting point: Should the one who pays always call the tune? Public organisations that fund research distribute public funds, and they are in the end accountable to the public. What is more, publicly funded research is a complex ecosystem with many stakeholders. When research funding agencies start using their newfound collective power to redefine how science is done, they will have to take responsibility for the result.

However one may evaluate Plan $S$ itself, it is great news that one of the key stakeholders in the science system takes responsibility and proposes bold action to solve major problems. The funding agencies have understood that the current situation is not sustainable and are willing to use their leverage in the system to change scientific publication practices. In order to make the Plan S successful, however, also the evaluation of scientists will have to be changed radically. ${ }^{13}$ As a result of this insight, cOAlition $S$ is increasingly committed to drive change not only in the Open Access debate but also in how scientists are evaluated. It is to be expected that new interventions in evaluation practices will have other ripple effects in the research ecosystem, which may have to be overhauled in fundamental 
ways. ${ }^{14}$ This is a heavy responsibility to bear, but public organisations that fund research can and should be held accountable for the policies they implement and promote. The public can expect that their interventions indeed bring positive change for science and society.

Funding agencies are also waking up to the fact that their new policies have a direct impact on the scientific community and especially on young researchers, who are the most affected by the new guidelines. Young researchers will have to adapt to a time of uncertainty while the system changes. What is expected of them, the way in which they publish, how they get funding, how they are assessed, and even the infamous "publish or perish" culture may look quite different once the dust is settled, and this has a direct impact on their livelihood, career path and life plans. Given the major disturbance funding agencies can create in the fragile equilibrium of the research ecosystem, one would expect that the scientific community has a voice in which policies should be pursued. Again, despite claims of the opposite, cOAlition $S$ has worked hard to involve the scientific community. From the start, RobertJan Smits consulted widely with stakeholders and since then cOAlition $S$ has ran and continues to run extensive consultations on aspects of Plan $S$ and its implementation. ${ }^{15}$ They have also done a special effort to listen to the concerns of young scientists. ${ }^{16}$ Nevertheless, research funding agencies usually do not have structural ways to hear the voice of the scientific community and early career scientists in particular. Their involvement is not structurally anchored in the governance of research funding agencies but only depends on the goodwill and good sense of the current directors.

If research funding agencies start to redefine how science is done, the scientific community and early career researchers in particular, need to have a seat at the table. We need to work together to overhaul the science ecosystem. This means adequate representation of different constituencies of the scientific community (taking into account generational, gender, disciplinary and geographical diversity) in the governance and policy levels of research funding agencies so that consultation and participation is ensured at all levels of policy design and decision making. Young researchers should be represented in both regional and national funding agencies as well as in their transnational coalitions.

1 The call for more research funding is continuous, highlighting its importance for innovation, economic growth and national security. See e.g. National Academy of Sciences, National Academy of Engineering, and Institute of Medicine. 2007. Rising Above the Gathering Storm: Energizing and Employing America for a Brighter Economic Future. Washington, DC: The National Academies Press. https://doi.org/10.17226/11463. National Research Council. 2012. Research Universities and the Future of America: Ten Breakthrough Actions Vital to Our Nation's Prosperity and Security. Washington, DC: The National Academies Press. https://doi.org/10.17226/13396.

2 There is strong criticism of how funding agencies operate: grant reviewing is very costly to the scientific system, especially in the time spent by researchers to prepare applications with a very low success rate, but also in the time spent by reviewers. Furthermore, it appears to be unreliable and may be subject to all sorts of biases. Some notable alternative suggestions include funding people, not projects (loannidis, J. Fund people not projects. Nature 477, 529-531 (2011). doi: 10.1038/477529a) or allocating 
research funding randomly. Ferric C. Fang, Arturo Casadevall. Research Funding: the Case for a Modified Lottery. mBio 7(2), e00422-16 (2016). doi: 10.1128/ mBio.00422-16.

3 Patricia Silveyra, Tyrone Grandison. The Obstacle Course to Research Independence and Innovation: Challenges for Early-Career Scientists, Trends in the Sciences 289, 58-61 (2020).

Herbert DL, Coveney J, Clarke P, Graves N, Barnett AG. The impact of funding deadlines on personal workloads, stress and family relationships: a qualitative study of Australian researchers, BMJ Open 4, e004462 (2014). doi: 10.1136/bmjopen-2013-004462.

4 Examples are Science Europe, the European association of research performing funding organisations founded in 2011, and the Global Research Council (GRC), a grouping of the heads of research councils from all over the world, founded in 2012. See https://www.scienceeurope.org/ and https://www.globalresearchcouncil.org/

5 Only in 1975, the World Medical Association supported the requirement of advance approval by an independent committee before a project can be initiated.

6 https://www.scienceguide.nl/2018/02/robert-jan-smits-tobecome-special-envoy-open-access-eu/

7 Robert-Jan Smits also consulted with me and Moritz Riede, as representatives of the Global Young Academy, to get input from the early career scientist community. He has personally told us the anecdote about Elsevier's CEO.

$8 \mathrm{https}$ ://www.coalition-s.org/addendum-to-the-coalitions-guidance-on-the-implementation-of-plan-s/principlesand-implementation/

9 A coalition of Young Academies has outlined two extreme scenarios of what could possibly happen. https:// globalyoungacademy.net/wp-content/uploads/2018/10/ YA-Statement-on-Plan-S-FINAL.pdf

10 See most famously the open letter: https://sites.google. $\mathrm{com} / \mathrm{view} /$ plansopenletter/open-letter.

11 This quote comes from one reaction to the Open Letter: https://www.fairopenaccess.org/wp-content/ uploads/2018/11/FOAA-reaction-to-Open-Letter.pdf

12 Researchers' manuscripts are routinely rejected, they are usually restricted to peer-reviewed outlets, there are disciplinary constraints, lists of accredited journals have been imposed, predatory journals are not accepted, etc.

13 This was publicly recognized by cOAlition $S$ at the 14th Berlin Open Access Conference, 3-4 December 2018. stressed this point here: https://www.nature.com/articles/ d41586-018-07659-5

14 Science Europe is very explicit in that it uses its expertise to advocate and shape science policy and funding. They have priority projects in Open Access, Research assessment, sharing of research data, increased crossborder collaboration.
15 cOAlition S collected more than 600 feedback statements on the draft implementation guidance of Plan $S$ and made these openly available: https://zenodo.org/record/3250081. Recently, cOAlition S consulted on transformative journals: https://www.coalition-s.org/coalition-s-consults-ontransformative-journals/

16 Robert-Jan Smits contacted the Global Young Academy very early in the process of developing Plan $S$ and cOAlition $S$ has taken up our proposal to create a continuous monitor that would measure the effects of Plan $\mathrm{S}$, with special attention to the effects on the practices and careers of early career scientists. cOAlition $\mathrm{S}$ has also been working with other early career scientist organizations. I am currently a member of the cOAlition S Task Force to design a Monitor that tracks the impact of Plan $\mathrm{S}$. 